\title{
SIMULATION OF PHYSICAL AND CHEMICAL PROCESSES IN FLOW-THROUGH DIAPHRAGM ELECTROLYTIC CELL FOR AGRICULTURE
}

\author{
Sergei Oskin, Dmitry Tsokur \\ Kuban State Agrarian University named after I.T. Trubilin, Russia \\ kgauem@yandex.ru,dmitry_tsokur@mail.ru
}

\begin{abstract}
Solutions of anolyte and catholyte obtained during diaphragm electrolysis as disinfectants or biostimulants are widely used not only in industry, but also in agriculture. One of the advantages of these solutions in comparison with traditional means is their environmental friendliness. Despite this, the mass application of these solutions in crop production, animal husbandry and other branches of agriculture is still difficult due to the lack of reliable flow-through installations for their production. This is primarily due to the low operational life of such installations. Modeling the processes occurring in diaphragm electrolyzers would simplify the process of their implementation in agriculture by improving their design. The conducted literature search showed the absence of mathematical models that would take into account the thermal, hydrodynamic and electrochemical processes occurring in flow-through diaphragm electrolyzers. The article deals with the simulation of these processes using the Comsol Multiphysics software. As a result of the simulation, images of the water $\mathrm{pH}$ in anode and cathode chambers of the electrolyzer, as well as temperature fields, were obtained and analyzed. It is determined that there is a section, after which the $\mathrm{pH}$ of the anolyte and the catholyte does not change significantly, what reduces the weight and size parameters of the installation in the channels of the flow-through diaphragm electrolyzer. A comparison of obtained theoretical and experimental data showed good convergence, which indicates the adequacy of the obtained mathematical model of physical and chemical processes in a flow-through diaphragm cell and the possibility of its further use for improving these installations in agriculture.
\end{abstract}

Keywords: flow-through diaphragm water electrolyzer, anolyte, catholyte, agriculture, Comsol Multiphysics.

\section{Introduction}

Water electrolysis has become widespread not only in industry, but also in agriculture. For example, solutions obtained in the process of diaphragm electrolysis (anolyte and catholyte) can be effectively used in crop production, animal husbandry and beekeeping $[2,3,4,7,8]$. This widespread use is due to the properties of anolyte and catholyte. Anolyte is an excellent disinfectant, and catholyte is a biostimulant. The most important thing is that these solutions are environmentally friendly and do not have a harmful effect on plants, animals and humans. But due to the low operational characteristics of plants for obtaining these solutions, the introduction of this technology is difficult in agriculture. It is quite obvious that the implementation process can be accelerated by developing a mathematical model of a flow-through diaphragm water cell. This will allow reducing the number of prototypes of the installation being developed, as well as the time spent on researching their operation.

\section{Materials and methods}

The difficulty of modeling such installations is due to the fact that in addition to thermal and hydrodynamic problems, it is necessary to take into account the electrochemical processes occurring on the electrodes and in the electrolyte, that is, to take into account chemical reactions, their velocities, direction, exchange current densities, etc [9]. To date, it is becoming clear that it is impossible to implement such installations in agriculture without the development of a model that would take into account all the above processes, as well as their interrelationships.

The closest one is the mathematical model developed by S. P. Voloshin at the Kuban State Agrarian University. It takes into account not only thermal and hydrodynamic processes, but also electrochemical processes occurring on the surface of electrodes and in the electrolyte itself. Its main drawback is that it was developed for a non-flowing diaphragm water electrolyzer, which is used in beekeeping for disinfection of bee hives [1]. Due to the low productivity (up to $2 \mathrm{l} \cdot \mathrm{h}^{-1}$ ), the use of this electrolyzer in crop production and animal husbandry is difficult. In these industries, in our opinion, the minimum capacity of electrolyzers should be from $40 \mathrm{l} \cdot \mathrm{h}^{-1}$ or more. Therefore, the mathematical model of a nonflowing diaphragm electrolyzer obtained by Voloshin S. P. is taken by us as a prototype.

The flow-through diaphragm electrolyzer of water solutions developed and studied by us consists of cathode and anode chambers. The channels have a zigzag shape and are cut into a $4 \mathrm{~mm}$ thick sheet of rubber. The diaphragm is made of tarpaulin. The electrodes are made of stainless steel and have 
terminals for connection to the electrical network. The water supply to the channels is carried out through the lower pipes, and the output of the resulting solutions through the upper ones. It allows to fill completely the channels of the anode and cathode chambers with water. Plexiglass with a thickness of $10 \mathrm{~mm}$ was used to insulate the electrodes. The installation dimensions are $370 \times 180 \times 40 \mathrm{~mm}$. Figure 1 shows the developed geometric model and a photo of the installation.
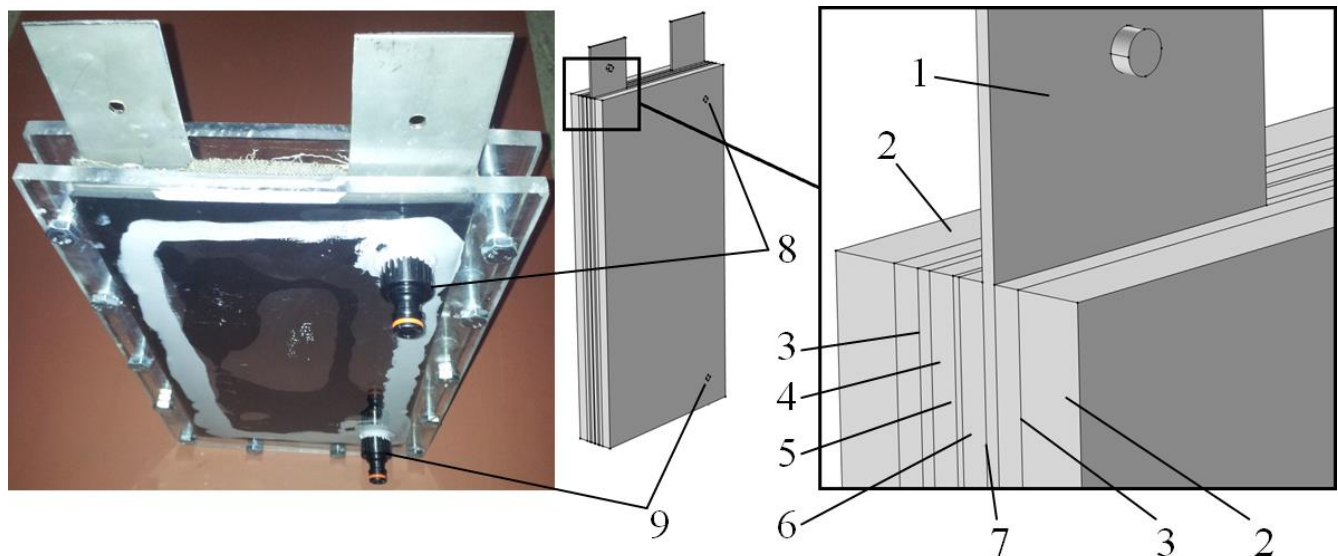

Fig. 1. Flow-through diaphragm water electrolyzer: 1 - anode; 2 - plexiglass; 3 - rubber pad; 4 - cathode; 5 - sheet of rubber in which the channel of the cathode chamber was cut; 6 - diaphragm; 7 - sheet of rubber in which the channel of the anode chamber was cut; 8 - output fittings; 9 -input fittings

The model of physical and chemical processes of such an installation will differ from the non-flow one by adding input and output hydrodynamic conditions. Condition at the liquid input to the electrolyzer [5]:

$$
u=-U_{0} n,
$$

where $u$-velocity of liquid flow, $\mathrm{m} \cdot \mathrm{s}^{-1}$;

$U_{0}-$ normal velocity of liquid flow, $\mathrm{m} \cdot \mathrm{s}^{-1}$;

$n$ - normal vector.

Condition at the liquid output from the electrolyzer [5]:

$$
\begin{gathered}
\left(-p I+\mu\left(\nabla u+(\nabla u)^{T}\right)-\frac{2}{3} \mu(\nabla \cdot u) I\right) n=-\hat{p}_{0} n, \\
\hat{p} \leq p_{0}
\end{gathered}
$$

where $T$-temperature, ${ }^{\circ} \mathrm{C}$;

$p$ - pressure in the installation, $\mathrm{Pa}$;

$\mu$ - coefficient of dynamic viscosity, $\mathrm{Pa} \cdot \mathrm{s}$;

$I$ - single vector.

The model assumed a laminar fluid flow described by the Navier-Stokes's equations in the formulation for a weakly compressible fluid:

$$
\left\{\begin{array}{l}
\frac{\partial \rho}{\partial t}+\nabla \cdot(\rho u)=0 \\
\rho \frac{\partial u}{\partial t}+\rho u \cdot \nabla u=-\nabla p+\nabla \cdot\left(\mu\left(\nabla u+(\nabla u)^{T}-\frac{2}{3} \mu(\nabla \cdot u) I\right)\right)+F+\rho g
\end{array},\right.
$$

where $F$-additional power pressure, $\mathrm{H} \cdot \mathrm{m}^{-3}$;

$\rho g$ - gravity force.

The following assumptions and boundary conditions were used in the simulation.

1. The heat exchange of the installation with the environment is due to convection.

2. The diaphragm is represented by a porous body half filled with water. 
3. The sliding condition is applied to the walls of the channels of the anode and cathode chambers:

$$
u \cdot n=0, \quad\left(-p I+\mu\left(\nabla u+(\nabla u)^{T}\right)\right) n=0 .
$$

4. The fluid velocity in the diaphragm is 0 .

5. When calculating electrochemical processes, the condition of electrical neutrality was regarded.

6. The kinetics of electrode processes was described using the Butler-Vollmer equation $[6,10]$ :

$$
i_{l o c}=i_{0}\left(\left(\alpha_{a}+\alpha_{c}\right) \frac{F}{R T} \eta\right),
$$

where $\alpha_{a}, \alpha_{c}$-coefficient of transfer for anode and cathode processes, respectively;

$\eta$ - overvoltage of an electrode, $\mathrm{V}$;

$i_{0}$ - density of current exchange, $\mathrm{A} \cdot \mathrm{m}^{-2}$;

$F$ - constant of Faraday, $\mathrm{Kl} \cdot \mathrm{mol}^{-1}$;

$R$ - gas constant, $\mathrm{J} \cdot \mathrm{mol}^{-1} \cdot \mathrm{K}^{-1}$.

7. Density of current exchange $i_{0}$ was calculated in the formula:

$$
i_{0}=n \cdot F \cdot k_{c}^{0,5} k_{a}^{0,5} C_{o x}^{0,5} C_{r e d}^{0,5},
$$

where $n$-number of electrons participating in the reaction;

$k_{a}, k_{c}$ - constant of a reaction's velocity in the anode and cathode, respectively, $\mathrm{m} \cdot \mathrm{s}^{-1}$;

$C_{o x}, C_{\text {red }}$ - concentrations of oxidants and reductants, $\mathrm{mol} \cdot \mathrm{m}^{-3}$.

8. The current supplied to the electrolyzer electrodes is $1 \mathrm{~A}$.

9. The water velocity at the entrance to the electrolyzer is $0.2 \mathrm{~m} \cdot \mathrm{s}^{-1}$.

10. $\mathrm{pH}$ of water in the entrance is 7 .

11. The following chemical reactions were taken into account at the anode:

$$
\begin{gathered}
2 \mathrm{H}_{2} \mathrm{O}-4 e^{-} \rightarrow 4 \mathrm{H}^{+}+\mathrm{O}_{2}, \\
2 \mathrm{Cl}^{-}-2 e^{-} \rightarrow \mathrm{Cl}_{2} .
\end{gathered}
$$

12. On the cathode:

$$
2 \mathrm{H}_{2} \mathrm{O}+2 e^{-} \rightarrow \mathrm{H}_{2}+2 \mathrm{OH}^{-} \text {. }
$$

\section{Results and discussion}

The main task to be solved was to determine the rational length of the channels of the electroactivator chambers. It is logical to assume that the change in the $\mathrm{pH}$ of the anolyte and the catholyte ends at a certain section of the channel and its further continuation is not rational, since it leads to an increase in the size of the installation. The mathematical models were processed in the Comsol Multiphysics software product. The results of the simulation were images of $\mathrm{pH}$ solutions in the electrolyzer (Fig. 2).
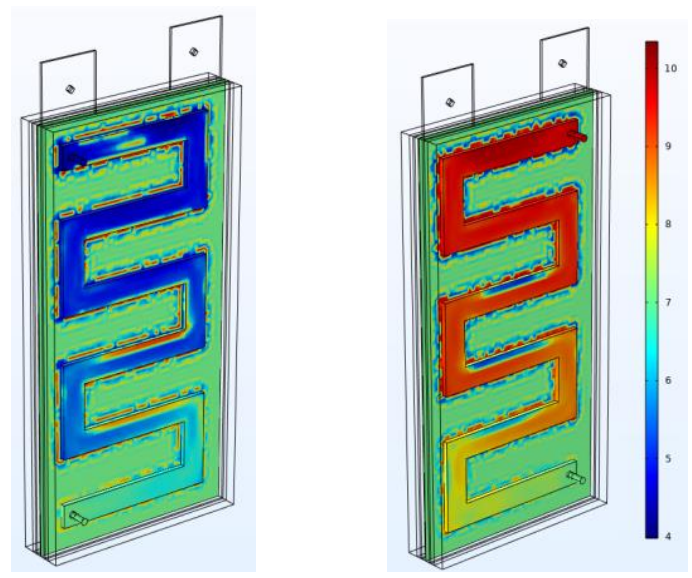

Fig. 2. Change of water pH: in the anode chamber (left) and in the cathode chamber (right) 
As expected, there is a section in the channels, after which it does not make sense to continue it, since the $\mathrm{pH}$ of the anolyte and catholyte does not change significantly. This is clearly seen in the crosssection of the water cell and the $\mathrm{pH}$ change graph shown in Figure 3. Starting from a height of $0.2 \mathrm{~m}$, the further $\mathrm{pH}$ change is not significant and does not exceed 0.2.

Images of temperature fields were obtained. We can see how the water gradually heats up, although the temperature difference at the input and output hardly exceeds 2 tenths of a degree at current of $1 \mathrm{~A}$ (Fig. 4).

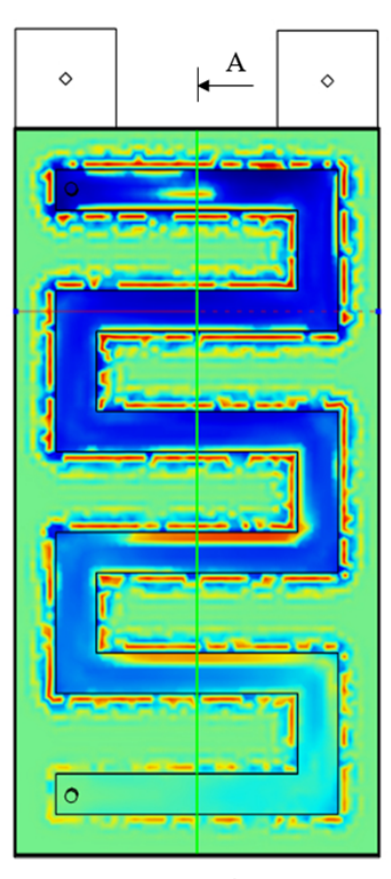

A
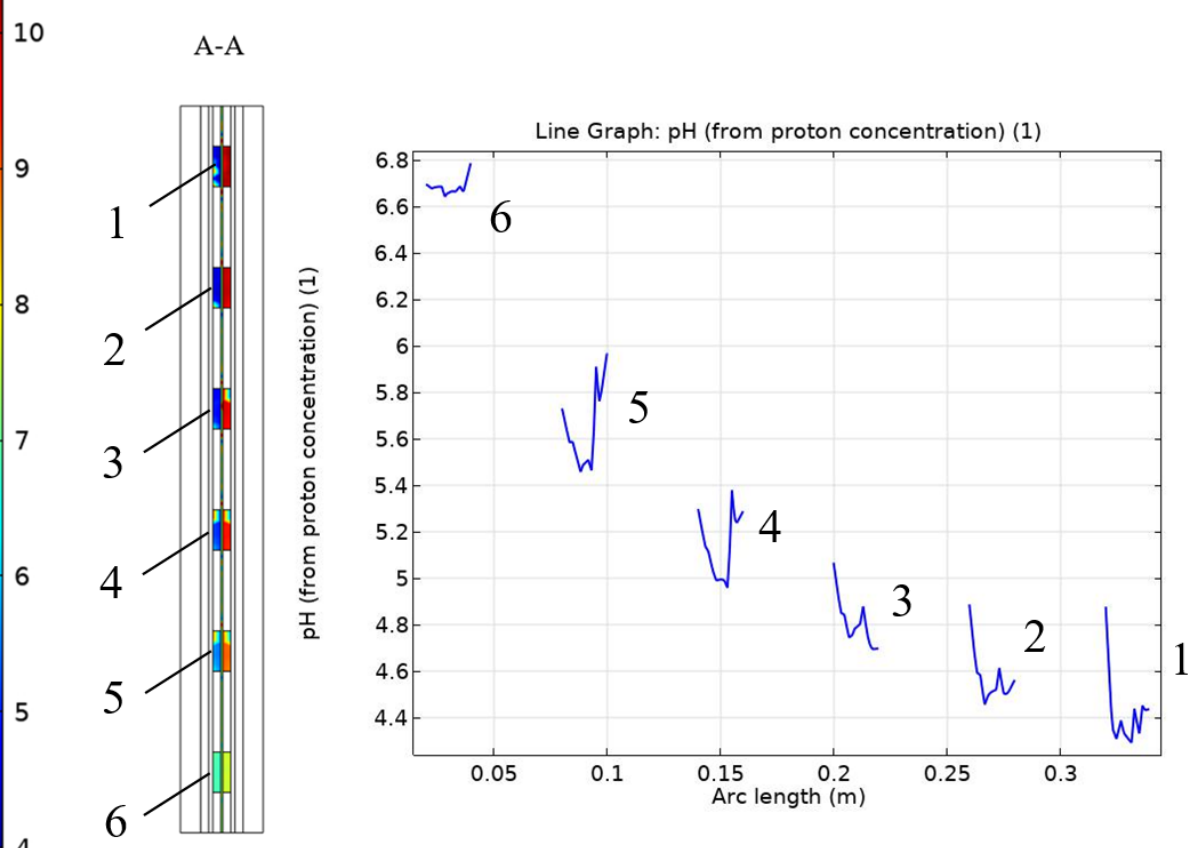

Fig. 3. Flow-through cross-section of the electrolyzer (left) and graph of $\mathrm{pH}$ change (right) in channels shown in cross-section

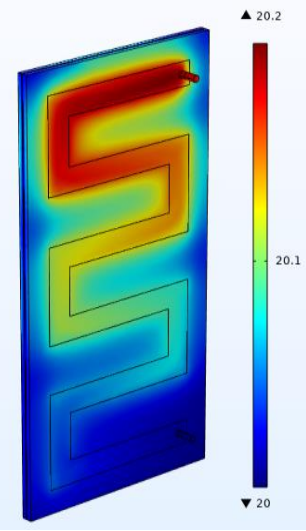

Fig. 4. Image of a temperature field in one of the chambers of the electrolyzer

\section{Conclusions}

The resulting model of physical and chemical processes in a flow-through water cell allows not only to justify the length of the channels of the anode and cathode chambers, but also to study further the changes in the shape of the channel, as well as to solve one of the main problems of such installations - clogging the pores of the diaphragm with salts.

It is proved that there is a section inside the anode and cathode chambers, after which it makes no sense to continue the channel, since further $\mathrm{pH}$ changes are insignificant. For each installation, this section must be selected individually, so its location will depend on many factors taken into account in 
the model: geometric dimensions (the distance between electrodes, the cross-sectional area of the channels of the cathode and anode chamber, etc.), electrical parameters, the chemical water composition (the amount of salts in it). The latter is very important and before implementing such flow installations it is necessary to analyze the local water to obtain the required parameters of the anolyte and catholyte.

\section{References}

[1] Voloshin S.P. Parameters and modes of combined electric activating installation to obtain disinfectant solutions in beekeeping: Abstract of PhD thesis in Engineering. - Krasnodar, 2019.

[2] Simonov N.M. Electrical activation of water resources applied in technological processes in AIC. Mechanization and electrification of agriculture, No. 5, 2000. pp. 31-32.

[3] Cheba B.P., Boltrik O.P. Activated water in hen drinking. Mechanization and electrification of agriculture, No 5, 1996. pp. 24-25.

[4] Al-Haq M.I., Sugiyama J., Isobe S.. Review Applications of Electrolyzed Water in Agriculture \& Food Industries. Food Science and Technology Research 11(2), 2005.

[5] CFD Module User's Guide. COMSOL.

[6] Electrochemistry Module User's Guide. COMSOL.

[7] Bessarabov D., Millet P. Fundamentals of Water Electrolysis. PEM Water Electrolysis, 2018. pp. 43-73.

[8] Aronbaev D.M., Aronbaev S.D., Raimkulova C.A. etc. Water "living" and "dead". New facts about antioxidant and relaxation characteristics of electroactivated water. 2021. pp. 26-31.

[9] Kashapov L., Fahretdinova E.I., Chebakova V.Y. On mathematical models of water electrolysis processes. 2020. pp. 74-80.

[10] LeeJ., Alam A., Ju H. Multidimensional and transient modeling of an alkaline water electrolysis cell. International Journal of Hydrogen Energy 46(26), 2020. pp. 13678-13690. 